J. Lake Sci. (湖泊科学), 2015, 27 (6) : 1004-1010

DOI 10. 18307/2015. 0603

(C) 2015 by Journal of Lake Sciences

\title{
鄱阳湖流域饶河鱼类稳定同位素比值和营养级的空间变化"
}

\author{
张 欢 ${ }^{1,4}$, 肖协文 ${ }^{1,3}$ ，王玉王 ${ }^{2}$ ，于秀波 ${ }^{1 * *}$ \\ (1: 中国科学院地理科学与资源研究所生态网络监测与模拟重点实验室, 北京 100101) \\ (2: 北京林业大学自然保护区学院,北京 100083) \\ (3: 中国科学院西双版纳热带植物园, 㔚腊 666303) \\ (4: 中国科学院大学, 北京 100049)
}

摘 要: 由于水文特征的变化和栖息生境的异质性, 河流食物网结构存在着一定的空间变化. 认识人类活动对河流食物 网结构空间变化的影响能够为河流生态系统的科学管理提供有效指导. 利用稳定同位素分析技术, 测定枯水季节饶河不 同地区初级生产者和鱼类的碳、氮稳定同位素比值 $\left(\delta^{13} \mathrm{C}\right.$ 和 $\left.\delta{ }^{15} \mathrm{~N}\right)$, 比较饶河下游鄱阳和中游海口河段 4 种常见鱼类的 $\delta^{13} \mathrm{C} 、 \delta^{15} \mathrm{~N}$ 值和营养级, 并分析导致不同河段食物网结构差异的原因. 结果表明, 鄱阳与海口两个地区鱼类的 $\delta^{13} \mathrm{C}$ 值无显 著差异, 但 $\delta^{15} \mathrm{~N}$ 值差异显著. 鱼类的 $\delta^{13} \mathrm{C}$ 值变化范围在鄱阳河段大于海口河段, 鳇 ( Siniperca chuatsi) 和贝氏䱗 (Hemiculter bleekeri) 在鄱阳河段的 $\delta^{15} \mathrm{~N}$ 值要显著高于海口河段, 而黄滪鱼 (Pelteobagrus fulvidraco) 和鲫 (Carassius auratus) 的 $\delta^{15}$ $\mathrm{N}$ 值在鄱阳河段却表现更低. 另一方面, 除黄滪鱼外, 鳊、贝氏餐和鲫在鄱阳河段的营养级均显著高于其在海口河段的营 养级. 研究认为, 由于颗粒有机物和附着藻类的 $\delta^{13} \mathrm{C}$ 值在鄱阳与海口河段没有显著差异, 因而导致鱼类的 $\delta^{13} \mathrm{C}$ 值也没有 明显变化. 不同生境下初级食物源 $\delta^{15} \mathrm{~N}$ 值的差异及人为扰动的程度可能是影响饶河不同河段鱼类的 $\delta^{15} \mathrm{~N}$ 值存在明显 差异的主要原因.

关键词 : 鱼类;饶河;空间变化;稳定同位素分析;营养级; 鄱阳湖

\section{Spatial variation instable isotope signatures and trophic position of fish in Raohe River, Lake Poyang Basin}

\author{
ZHANG Huan ${ }^{1,4}$, XIAO Xiewen ${ }^{1,3}$, WANG Yuyu ${ }^{2} \&$ YU Xiubo ${ }^{1}$ \\ (1: Key Laboratory of Ecosystem Network Observation and Modeling, Institute of Geographic Sciences and Natural Resources \\ Research, Chinese Academy of Sciences, Beijing 100101, P. R. China) \\ (2: College of Nature Conservation, Beijing Forestry University, Beijing 100083, P. R. China) \\ (3: Xishuangbanna Tropical Botanical Garden, Chinese Academy of Sciences, Mengla 666303, P. R. China) \\ (4: University of Chinese Academy of Sciences, Beijing 100049, P. R. China)
}

\begin{abstract}
Due to the flow variability and habitat heterogeneity, spatial variation of river food web structure has been well understood. However, disturbance from anthropogenic activities, especially urbanization or eutrophication, may influence the spatial dynamic in food web structure of rivers. Further understanding of this spatial variation will provide available information for scientific management of lotic ecosystems. In this study, we used stable isotope analysis to investigate the $\delta^{13} \mathrm{C}$ and $\delta^{15} \mathrm{~N}$ signatures of primary food sources and fish (Siniperca chuatsi, Hemiculter bleekeri, Pelteobagrus fulvidraco, Carassius auratus) in Raohe River during the dry period. Based on $\delta^{15} \mathrm{~N}$ values, trophic position of four predominant fish species were calculated in urbanized (Poyang Section) and less urbanized reaches(Haikou section), respectively. Differences in isotopic values and trophic position of fish were then compared to determine if these changes were related to urbanization and river habitats. Little variation in $\delta^{13} \mathrm{C}$ values of fish was observed between Poyang and Haikou areas, which could be reflected by the values of particulate organic matter and attached algae. However, markedly differences were examined in $\delta^{15} \mathrm{~N}$ values of fish species from those sampling areas. $\delta^{15} \mathrm{~N}$ values in $S$.
\end{abstract}

* 国家自然科学基金项目(41171030,41471088)资助. 2014-11-23 收稿;2015-04-21 收修改稿. 张欢( 1986 ), 男,博士研究生; E-mail: zhangh.13b@igsnrr. ac.cn.

** 通信作者;E-mail: yuxb@ igsnrr. ac. cn. 
chuatsi and $H$. bleekeri from Poyang section were significantly higher than those in Haikou section, but C. auratus and P. fulvidraco had much lower values in Poyang section. Moreover, S. chuatsi, H. bleekeri and C. auratus had higher trophic positions in Poyang section than those species in Haikou section except for $P$. fulvidraco. Our data suggested that $\delta^{15} \mathrm{~N}$ values of basal energy sources and eutrophication caused by anthropogenic activities could be the important factors that affected the nitrogen isotopic signatures of fish in different areas of Raohe River.

Keywords: Fish; Raohe River; spatial variation; stable isotopes; trophic position; Lake Poyang

“河流连续性概念” 的研究使人们认识到河流生态系统的结构和功能存在一定的空间变化. 在人类活动 干扰较小的河流中, 不同河段的栖息地环境和生物组成具有较为明显的差异 ${ }^{[1-2]}$. 然而, 人为活动的干扰, 尤其 是城镇化发展对河流生态系统存在着巨大的影响, 导致河流的空间变化与连续性概念的描述不完全一致 ${ }^{[34]}$. 在香溪河的研究表明,附着藻类、叶绿素 $\mathrm{a}$ 浓度和生物多样性指数在不同的河段存在着不同的变化趋势 ${ }^{\left[{ }^{[3]}\right.}$. 另 外,Pusey 等 ${ }^{[5]}$ 发现 Burdekin 河鱼类的食物组成没有因水坝的地理阻隔作用而产生明显的空间差异. 开展对河 流中生物组成及其营养关系的空间变化研究, 能够为河流生态系统的认识与管理提供有效的指导.

由于绕河流域内矿产资源丰富, 大多数研究集中关注重金属污染和水质问题, 对其生态系统的相关研 究则很少 ${ }^{[6-7]}$. 另外, 作为主要的人湖河流之一, 饶河与鄱阳湖之间存在着复杂的物质与能量流通过程, 饶河 生态系统的变化可能对鄱阳湖生态系统产生影响, 因此对饶河生态系统的相关研究具有十分重要的意义. 作为一种有效的分析手段, 稳定同位素技术在研究如食物网结构 ${ }^{[8]}$ 、营养生态位 ${ }^{[9]}$ 、生物人侵 ${ }^{[10]}$ 及重金属 富集 ${ }^{[11]}$ 等科学问题方面都有广泛的应用. 本研究利用碳、氮稳定同位素分析技术, 以 4 种重要的经济鱼 类一一鳜、贝氏䱗、黄颡鱼和鲫为主要研究对象, 测定了枯水季节饶河不同地区的初级食物源和鱼类的稳定 同位素比值. 通过比较饶河鄱阳与海口河段鱼类的 $\delta^{13} \mathrm{C} 、 \delta^{15} \mathrm{~N}$ 值和营养级, 探讨饶河鱼类营养关系是否存在 空间差异及可能原因.

\section{1 材料与方法}

\section{1 研究区域概况}

饶河 $\left(28^{\circ} 34^{\prime} \sim 30^{\circ} 02^{\prime} \mathrm{N}, 116^{\circ} 30^{\prime} \sim 118^{\circ} 13^{\prime} \mathrm{E}\right)$ 位于鄱阳湖主湖区东面, 由乐安河、昌江两大支流汇合组 成. 南支发源于敂源县北部的黄山余脉鄣公山, 流经嬖源、德兴、乐平、万年和鄱阳 5 县, 全长 $279 \mathrm{~km}$, 流域 面积 $8367 \mathrm{~km}^{2}$. 北支发源于安徽黄山脚下的祁门县境内, 流经景德镇市和鄱阳县, 全长 $253 \mathrm{~km}$, 流域面积 $6000 \mathrm{~km}^{2}$. 饶河流域山地、丘陵约占 $70 \%$, 平原只占 $30 \%$, 后者主要分布在下游滨湖地区 ${ }^{[12]}$. 饶河流域属于 亚热带季风湿润气候区, 多年平均气温在 $17.3^{\circ} \mathrm{C}$ 左右, 多年平均年降水量 $1850 \mathrm{~mm}, 10$ 月至次年 3 月枯水期 的降水量约占全年的 $31 \%$, 径流量约占全年的 $29 \%$.

饶河流域土地利用类型多样, 饶河上、中、下游从以森林景观为主, 逐渐向农田与城镇建设用地过渡. 本 实验选取饶河中游和下游的海口、鄱阳河段作为代表性研究区域(图 1).

\section{2 样品的采集与处理}

样品的采集工作在 2013 年 10 月份进行. pH 值、溶解氧、氧化还原电位和总溶解固体由 Horiba U52 型 多参数水质分析仪现场测定. 采集的水样冰冻后带回实验室分析, 总氮、总磷和叶绿素 a 浓度的测定参照文 献 $[13-14]$.

取混合河水水样, 过滤到预烧 $\left(500^{\circ} \mathrm{C}, 2 \mathrm{~h}\right.$ ) 的玻璃纤维滤膜( Whatman GF/F) 上, 获得含颗粒有机物质 的样品即为颗粒有机物 (POM). 水生植物和沿岸带的植物叶片用手直接采摘或采草器割取, 将附着在叶片 上的碎屑等杂质用清水冲洗干净. 用小刀和牙刷从石头上或螺、蛙的外壳上刮取附着藻类样品, 并在显微镜 下挑选出较为明显的杂质. 使用过量的 $1 \mathrm{~mol} / \mathrm{L}$ 盐酸溶液酸化处理 POM 和附着藻类样品, 去除可能存有的 碳酸盐, 以免影响 $\delta^{13} \mathrm{C}$ 值的测定. 为避免个体大小的影响, 挑选的鱼类样品均为成熟个体. 测量完每尾鱼样 品的全长、体重后, 取一小块背部白肌做为样品. 所有用于稳定同位素分析的样品均在 $60^{\circ} \mathrm{C}$ 下烘烤至恒重 后, 使用研钵将其研磨成均匀粉末, 放人干燥器中保存待测.

\section{3 稳定同位素比值分析}

所有样品的碳、氮稳定同位素分析均在中国科学院地理科学与资源研究所进行, 所用仪器为美国 


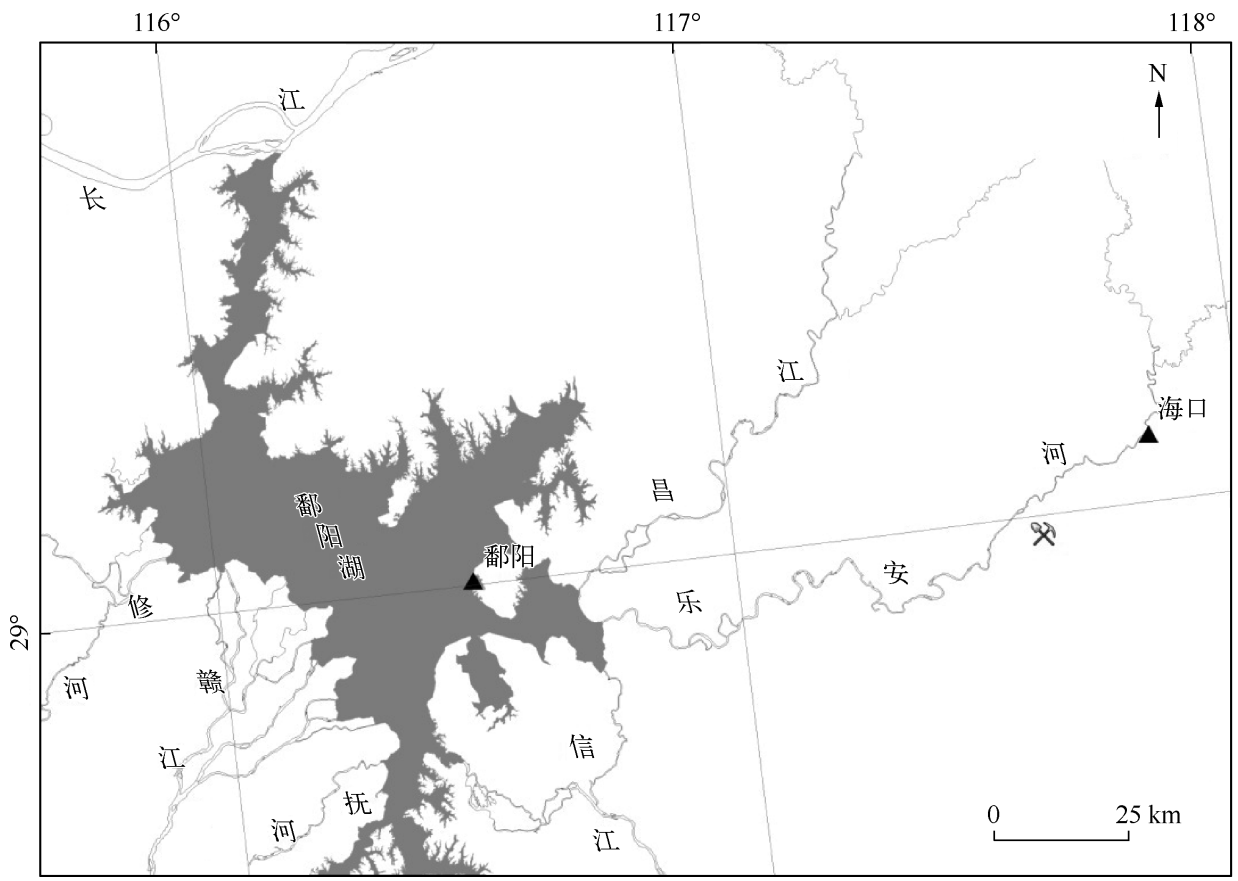

图 1 饶河流域采样河段的分布

Fig. 1 Distibution of sampling sites in the Raohe River Basin

Thermo公司的元素分析仪与 Delta Plus Finnigan MAT 253 同位素质谱仪. 碳、氮稳定同位素比值以 $\delta$ 值的形 式表达,定义为:

$$
\delta \mathrm{X}(\%)=\left[\left(R_{\text {sample }} / R_{\text {standard }}\right)-1\right] \times 1000
$$

式中, $R$ 代表 ${ }^{13} \mathrm{C}$ 或 ${ }^{15} \mathrm{~N}, R_{\text {sample }}$ 为所测得的同位素比值, C 同位素为 ${ }^{12} \mathrm{C} /{ }^{13} \mathrm{C}, \mathrm{N}$ 同位素为 ${ }^{14} \mathrm{~N} /{ }^{15} \mathrm{~N} ; R_{\text {standard }}$ 为标准 物质的同位素比值, $\mathrm{C} 、 \mathrm{~N}$ 稳定同位素测定的标准物质分别为 PDB (美洲拟箭石) 和空气中的 $\mathrm{N}_{2} ; \delta$ 值越小表 示样品重同位素 $\left({ }^{13} \mathrm{C}\right.$ 或 $\left.{ }^{15} \mathrm{~N}\right)$ 含量越低, 越大表示样品重同位素 $\left({ }^{13} \mathrm{C}\right.$ 或 $\left.{ }^{15} \mathrm{~N}\right)$ 含量越高. 每测定 10 个样品插人 1 个标准样品, 并随机挑选 $1 \sim 2$ 个样品进行复测. 样品 $\delta^{13} \mathrm{C}$ 和 $\delta^{15} \mathrm{~N}$ 重现精度为 $\pm 0.3 \%$.

\section{4 数据分析处理}

鱼类营养级的计算公式为: 营养级 $=\lambda+\left(\delta^{15} \mathrm{~N}_{\text {消费者 }}-\delta^{15} \mathrm{~N}_{\text {基准 }}\right) / 3.4 \%$, 式中 $\lambda$ 为基准生物的营养级,

表 1 饶河流域鄱阳和海口河段水体理化指标

Tab. 1 Water physic-chemical characteristics in

Poyang and Haikou section of Raohe River Basin

\begin{tabular}{lcc}
\hline 水质参数 & 鄱阳 & 海口 \\
\hline $\mathrm{pH}$ 值 & 6.83 & 7.31 \\
溶解氧 $/(\mathrm{mg} / \mathrm{L})$ & 8.12 & 15.06 \\
氧化还原电位 $/ \mathrm{mV}$ & 168 & 38 \\
总溶解固体 $/(\mathrm{mg} / \mathrm{L})$ & 0.218 & 0.062 \\
叶绿素 $\mathrm{a} /(\mu \mathrm{g} / \mathrm{L})$ & 0.084 & 0.004 \\
总氮 $/(\mathrm{mg} / \mathrm{L})$ & - & 4.16 \\
总磷 $/(\mathrm{mg} / \mathrm{L})$ & 0.1808 & 0.045 \\
周边环境 & 城镇 & 农村 \\
\hline
\end{tabular}

$3.4 \% 0$ 为每递增 1 个营养级 $\delta^{15} \mathrm{~N}$ 的富集常

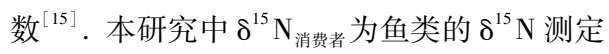

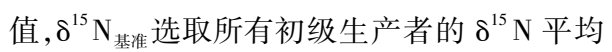
值, $\lambda$ 为 $1^{[16]}$.

利用 SPSS (Version 16.0) 统计软件对初 级食物源和鱼类样品 $\delta^{13} \mathrm{C} 、 \delta^{15} \mathrm{~N}$ 的空间差异 进行单因素方差( ANOVA) 分析.

\section{2 结果}

\section{1 水质监测情况}

水体理化指标监测情况表明 (表 1), 位 于饶河下游的鄱阳河段水体的总磷、叶绿素 a 浓度等多个指标均远大于海口河段, 主要与 2 
个研究区域的城镇化发展及周边环境有关.

\section{2 初级生产者的 $\delta^{13} \mathrm{C}$ 和 $\delta^{15} \mathrm{~N}$ 值}

在下游鄱阳河段,所有初级生产者的 $\delta^{13} \mathrm{C}$ 值范围为 $-28.7 \% 0 \sim-22.5 \% 0, \delta^{15} \mathrm{~N}$ 值范围为 $4.2 \% 0 \sim 8.5 \% 0$ (表 2). 在中游海口河段, 初级生产者的 $\delta^{13} \mathrm{C}$ 值范围更大, 为 $-30.7 \% 0 \sim-20.5 \% 0, \delta^{15} \mathrm{~N}$ 值范围为 $4.7 \% 0 \sim$ $9.0 \%$. 另外, 海口河段 POM 的 $\delta^{15} \mathrm{~N}$ 值显著大于鄱阳河段 $(F=53.687, P<0.05)$, 然而 POM 的 $\delta^{13} \mathrm{C}$ 值却 无显著差异 $(F=23.941, P=0.05)$. 同样, 附着藻的 $\delta^{13} \mathrm{C}$ 和 $\delta^{15} \mathrm{~N}$ 值在 2 个区域也没有显著差异 $(F=$ $0.015, P=0.914 ; F=0.436, P=0.577)$.

表 2 饶河流域鄱阳和海口河段生产者和鱼类样品的碳、氮稳定同位素比值

Tab. 2 Carbon and nitrogen isotopic values of the basal production sources and fish species sampled from Poyang and Haikou section of Raohe River Basin

\begin{tabular}{|c|c|c|c|c|c|c|c|c|}
\hline \multirow{2}{*}{ 种类 } & \multicolumn{4}{|c|}{ 鄱阳河段 } & \multicolumn{4}{|c|}{ 海口河段 } \\
\hline & $n$ & 全长/cm & $\delta^{13} \mathrm{C} / \%$ & $\delta^{15} \mathrm{~N} / \%$ & $n$ & 全长/cm & $\delta^{13} \mathrm{C} / \%$ & $\delta^{15} \mathrm{~N} / \%$ \\
\hline \multicolumn{9}{|l|}{ 初级食物源 } \\
\hline 颗粒有机物 POM & 5 & - & $-27.7 \pm 0.8$ & $4.9 \pm 0.5$ & 5 & - & $-26.1 \pm 0.6$ & $7.8 \pm 0.5$ \\
\hline 附着藻 & 3 & - & $-23.7 \pm 0.7$ & $5.1 \pm 0.3$ & 3 & - & $-23.3 \pm 1.1$ & $4.8 \pm 0.4$ \\
\hline 苦草(Vallisneria natans) & - & - & - & - & 1 & - & -30.7 & 8.8 \\
\hline 马来眼子菜(Potamogeton malaianus) & 1 & - & -23.8 & 5.2 & 1 & - & -28.9 & 9.0 \\
\hline 穗花狐尾藻( Myriophyllum spicatum) & 1 & - & -22.5 & 8.5 & - & - & - & - \\
\hline 轮叶黑藻( Hydeilla verticillata) & - & - & - & - & 3 & - & $-24.7 \pm 0.9$ & $7.7 \pm 0.7$ \\
\hline 苔草( Carex spp. ) & 1 & - & -23.4 & 7.1 & - & - & - & - \\
\hline 水蓼( Polygonum hydropiper) & 1 & - & -23.9 & 5.3 & 2 & - & $-27.6 \pm 1.5$ & $7.7 \pm 0.2$ \\
\hline 萎蒿(Artemisia selengensis) & 1 & - & -28.5 & 5.8 & - & - & - & - \\
\hline \multicolumn{9}{|l|}{ 鱼类 } \\
\hline 鳜 (Siniperca chuatsi) & 7 & $22.9 \pm 5.3$ & $-19.5 \pm 0.3$ & $14.5 \pm 1.2$ & 3 & $21.1 \pm 8.5$ & $-22.8 \pm 0.8$ & $12.5 \pm 0.5$ \\
\hline 贝氏䱗( Hemiculter bleekeri) & 5 & $16.3 \pm 1.8$ & $-25.2 \pm 0.4$ & $14.1 \pm 0.6$ & 6 & $14.8 \pm 1.5$ & $-24.7 \pm 0.5$ & $10.6 \pm 0.5$ \\
\hline 鲫(Carassius auratus) & 6 & $14.5 \pm 1.3$ & $-26.0 \pm 1.4$ & $11.2 \pm 1.7$ & 6 & $16.2 \pm 1.3$ & $-21.5 \pm 1.3$ & $11.5 \pm 0.7$ \\
\hline 黄颡鱼( Pelteobagrus fulvidraco) & 8 & $17.1 \pm 1.2$ & $-26.1 \pm 1.4$ & $11.6 \pm 1.7$ & 6 & $12.3 \pm 3.6$ & $-24.3 \pm 1.8$ & $12.1 \pm 1.1$ \\
\hline
\end{tabular}

\section{3 鱼类的 $\delta^{13} \mathrm{C}$ 和 $\delta^{15} \mathrm{~N}$ 值}

鄱阳河段与海口河段鱼类的 $\delta^{13} \mathrm{C}$ 值无显著差异 $(F=0.991, P=0.325)$, 然而 $\delta^{15} \mathrm{~N}$ 值的差异较为明 显 $\left(F=6.273, P<0.05\right.$ ) (表 2 和图 2). 其中, 鳜在鄱阳河段的 $\delta^{13} \mathrm{C}$ 值为 $-19.5 \% 0 \pm 0.3 \%$, 显著高于海口 河段 $(-22.8 \% 0 \pm 0.8 \% 0)\left(F=91.748, P<0.01\right.$, 图 2). 贝氏㛑、黄颡鱼和鲫在鄱阳河段的 $\delta^{13} \mathrm{C}$ 值均低于 海口河段, 但只有鲫表现出极显著差异 $(F=34.796, P<0.01)$. 另外, 鱼类的 $\delta^{13} \mathrm{C}$ 值变化范围在鄱阳河段 大于海口河段,表明鱼类在前者摄食的食物类型更多.

鳜、贝氏餐的 $\delta^{15} \mathrm{~N}$ 值在鄱阳河段分别为 $14.5 \% 0 \pm 1.2 \% 0 、 14.1 \% 0 \pm 0.6 \%$, 显著大于海口河段 $(F=$ $6.903, P<0.05 ; F=110.524, P<0.01$, 图 2). 与之相反, 在鄱阳河段黄颞鱼和鲫的 $\delta^{15} \mathrm{~N}$ 值均比海口河 段略低,但差异不显著 $(F=0.428, P=0.525 ; F=0.220, P=0.649)$.

\section{4 鱼类的营养级}

4 种鱼类的营养级在鄱阳和海口河段存在极显著差异 $(F=36.946, P<0.01$ ) (图 3). 其中, 䰻在鄱阳 河段的营养级为 $3.6 \pm 0.4$, 显著高于在海口河段的营养级 $(F=23.127, P<0.01)$. 贝氏䱗在鄱阳河段的 营养级为 $3.5 \pm 0.2$, 也显著高于其在海口河段的营养级 $(F=272.643, P<0.01)$. 虽然黄颡鱼和鲫在鄱阳 河段的营养级比海口河段高, 但差异并不显著 $(F=2.891, P=0.115 ; F=3.044, P=0.112)$.

\section{3 讨论}

由于水文特征和栖息生境的异质性, 河流中鱼类的群落结构在空间上存在着一定的变化 ${ }^{[17-19]}$. 虽然本 

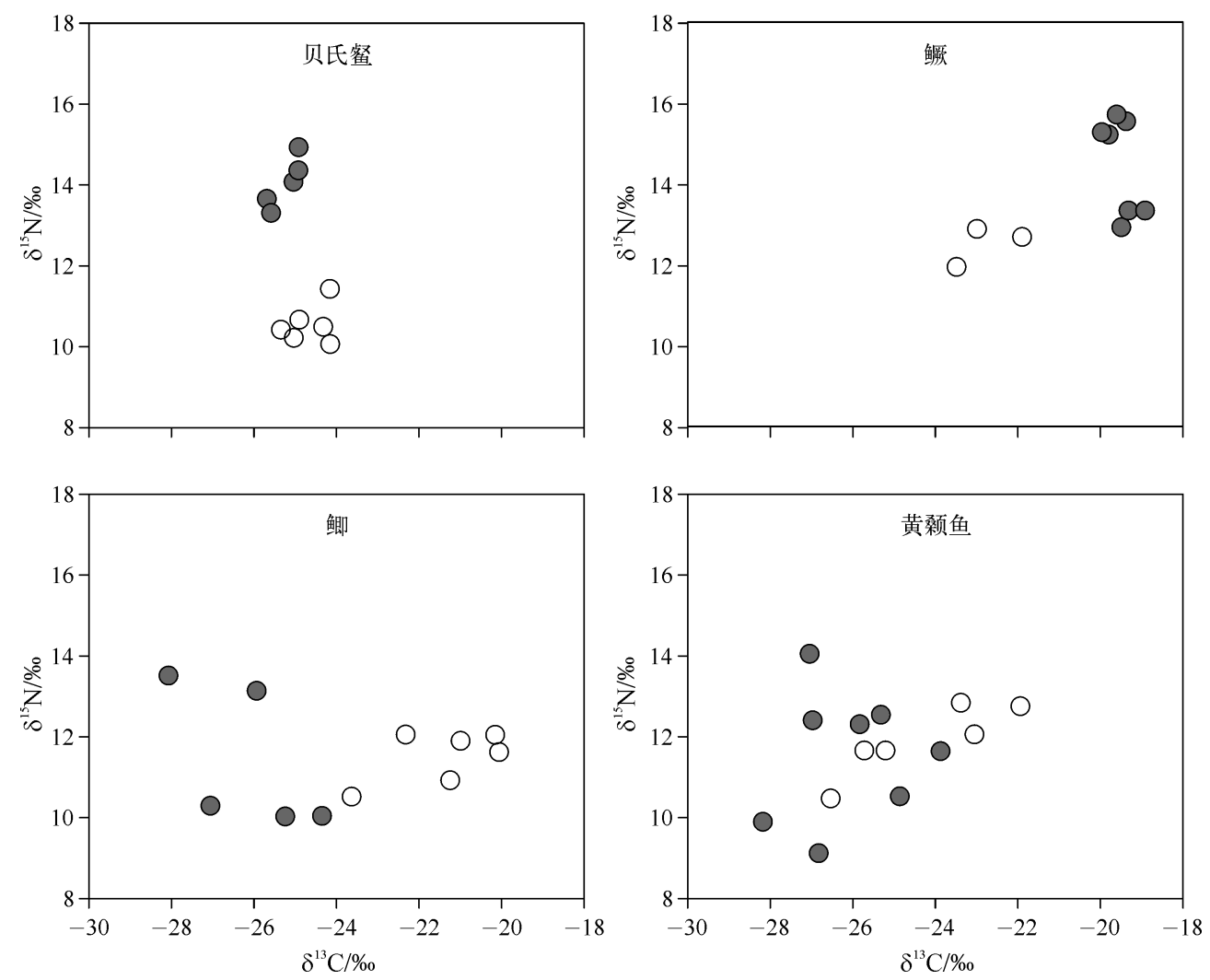

图 2 贝氏餐、鳜、鲫和黄颡鱼所有个体的碳、氮稳定同位素比值

Fig. 2 Carbon and nitrogen isotope ratio biplots of all individuals for

H. bleekeri, S. chuatsi, C. auratus and P. fulvidraco

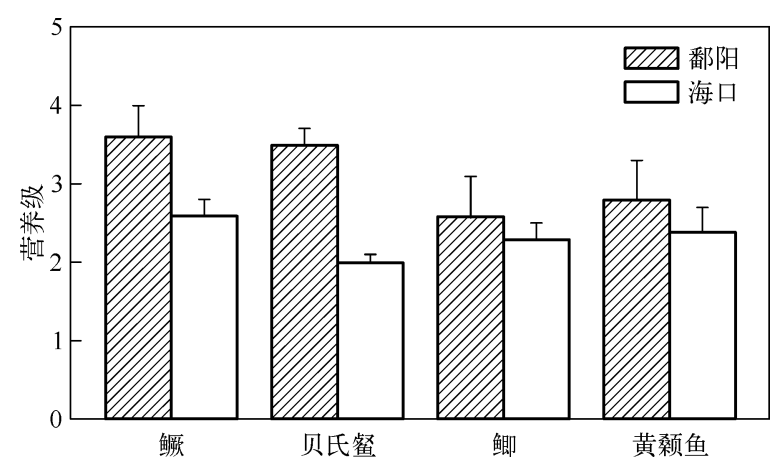

图 3 利用初级食物源作为基准物计算得到鄱阳 和海口河段鱼类的平均营养级

Fig. 3 Mean trophic position of fish species in Poyang and Haikou sections calculated using basal production sources
研究未对饶河鱼类的群落结构进行调查, 但发 现不同河段鱼类的 $\delta^{15} \mathrm{~N}$ 值表现出较为显著的 空间差异, 而 $\delta^{13} \mathrm{C}$ 值并没有明显的差异. 许多 研究表明 ${ }^{[18,20]}$, 鱼类的 $\delta^{13} \mathrm{C}$ 和 $\delta^{15} \mathrm{~N}$ 值主要与 河流的生境及饵料生物的变化有关. 由于选 择利用的食物源不同, 张亮 ${ }^{[19]}$ 发现三峡江段 鱼类的 $\delta^{13} \mathrm{C}$ 和 $\delta^{15} \mathrm{~N}$ 值存在着较为明显的坝上 和坝下差异.

在河流生态系统中, 藻类是大部分消费者 的重要初级食物来源 ${ }^{[21-22]}$. 特别是在枯水季 节, 由于鱼类等消费者的活动范围受到一定的 限制, 藻类被认为是维系河流食物网的主要碳 源 ${ }^{[22]}$. 在本研究中, POM 和附着藻类的 $\delta^{13} \mathrm{C}$ 值在鄱阳与海口河段没有显著性差异, 因而可 能导致鱼类的 $\delta^{13} \mathrm{C}$ 值没有显著差异. 另一方 面, 鄱阳和海口河段附着藻类的 $\delta^{15} \mathrm{~N}$ 值虽无 
显著差异, 然而 POM 的 $\delta^{15} \mathrm{~N}$ 值表现出显著差异, 因此可能导致 2 个河段鱼类的 $\delta^{15} \mathrm{~N}$ 值存在着较为明显的 变化.

含有大量 $\mathrm{N}$ 的农业污水和生活废水排人河流能够影响藻类等初级食物源的 $\delta^{15} \mathrm{~N}$ 值, 通过捕食关系对 鱼类等消费者的 $\delta^{15} \mathrm{~N}$ 值能够产生影响 ${ }^{[23-25]}$. 在不同程度的人类活动影响下, 王玉玉等 ${ }^{[26]}$ 发现鄱阳湖不同 区域鱼类的 $\delta^{15} \mathrm{~N}$ 值与 POM 的 $\delta^{15} \mathrm{~N}$ 值空间变化较为一致. 通过对饶河干流水质的监测, 本研究和张洁等 ${ }^{[7]}$ 均认为海口河段的富营养化程度远低于饶河下游区域. 同样, 胡绵好等 ${ }^{[27]}$ 也发现, 位于饶河下游的鄱阳县 和乐安县因为农业养殖活动排放的氮、磷导致饶河局部水体污染较为严重. 因此, 人类活动的影响也可能是 饶河不同区域鱼类的氮稳定同位素比值存在明显变化的重要原因之一.

由于水文特征和地貌形态的差异, 河流中、上游地区鱼类等消费者的丰度和生物多样性相比下游地区 要小 ${ }^{[1,28]}$, 因而下游河段能够为顶级捕食者提供更多的食物资源. 饵料生物的多样性越高, 则顶级捕食者摄 食到营养级较高的饵料生物的机会就越大, 因而顶级捕食者可能获得更高的营养级 ${ }^{[29]}$. 在饶河生态系统 中, 浮游动物的密度在海口河段最低, 而在下游地区如石镇最高 ${ }^{[7]}$. 因此, 位于绕河下游的鄱阳河段可能为 顶级捕食者提供更多的动物性饵料, 从而使得该河段鱼类获得较高的营养级. 另外, 作为顶级捕食者一一鲭 的潜在饵料生物, 黄颡鱼、贝氏䱗和鲫在鄱阳区域的营养级相比海口区域要高, 因此鳜在鄱阳河段也相应地 表现出较高的营养等级.

许多研究表明, 除了营养物质的输人外, 人类活动主要通过改变河岸带的生境从而对河流生态系统产 生影响 ${ }^{[4]}$. 河岸带的人工加固或改造都有可能导致沿岸植被的破坏, 从而减少陆源物质的贡献, 破坏河岸带 与主河道之间物质和能量的交换 ${ }^{\left[{ }^{[0]}\right.}$. 另外, 城市化引起土地覆被的改变还将导致河流生物类群的生物多样 性降低, 最终影响河流生态系统的结构与功能 ${ }^{[31]}$. 在饶河流域, 由于中游和下游地区的城镇化水平不同, 河 流富营养化程度也存在一定的空间差异,这些因素都可能影响鱼类的食物来源及营养级的空间变化.

\section{4 参考文献}

[ 1 ] Vannote RL, Minshall GW, Cummins KW et al. River continnum concept. Canadian Journal of Fisheries and Aquatic Sciences, $1980,37(1): 130-137$.

[ 2 ] Finlay JC, Khandwala S, Power ME. Spatial scales of carbon flow in a river food web. Ecology, 2002, 87 (3): 1845-1859.

[3] 唐 涛, 黎道丰, 潘文斌等. 香溪河河流连续统特征研究. 应用生态学报, 2004,15(1): 141-144.

[ 4 ] Eitzmann JL, Paukert CP. Urbanization in a great plains river: effects on fishes and food webs. River Research and Applications, $2010,26(8)$ : 948-959.

[ 5 ] Pusey BJ, Arthington AH, Stewart-Koster B et al. Widespread omnivory and low temporal and spatial variation in the diet of fishes in a hydrologically variable northern Australian river. Journal of Fish Biology, 2010,77(3) : 731-753.

[6]曾凡萍, 刘 澍, 肖化云等. 饶河入鄱阳湖口处沉积物中重金属的含量及空间变化. 环境科技, 2010,23(5): 5154.

[7] 张 洁, 潜小兰, 张力薇等. 饶河干流浮游动物时空分布特征及水质综合评价. 广东农业科学, 2013, 17: 164-167.

[ 8 ] Pace ML, Cole JJ, Carpenter SR et al. Whole-lake carbon-13 additions reveal terrestrial support of aquatic food webs. Nature, $\mathbf{4 2 7}(6971):$ 240-243.

[9] 张 欢, 谢 平, 吴功果等. 日本沼虾与秀丽白虾的营养生态位. 环境科学研究, 2013,26(1):22-26.

[10] Vander Zanden MJ, Casselman M, Rasmussen JB. Stable isotope evidence for the food web consequences of species invasions in lakes. Nature, $1999,401(6752)$ : 464-467.

[11] Bond AL, Diamond AW. Mercury concentrations in seabird tissues from Machias Seal Island, New Brunswick, Canada. Science of the Total Environment, $2009, \mathbf{4 0 7}(14)$ : 4340-4347.

[12] 傅国儒. 饶河. 中国水利, 1984,6: 36.

[13] 国家环境保护总局《水和废水监测分析方法》编委会. 水和废水监测分析方法. 第 4 版. 北京: 中国环境科学出版 社, 2002.

[14] 陈宇炜, 高锡云. 浮游植物叶绿素 a 含量测定方法的比较测定. 湖泊科学, 2000,12(2) : 185-188. DOI 10. 18307/ 
2000. 0215 .

[15] Post DM. Using stable isotopes to estimate trophic position: models, methods, and assumptions. Ecology, 2002,83(3): $703-718$.

[16] Zeug SC, Winemiller KO. Evidence supporting the importance of terrestrial carbon in a large-river food web. Ecology, $2008,89(6): 1733-1743$.

[17] Gibo KB, Propst DL, Jr Molles MC. Spatial and temporal variation of fish communities in secondary channels of the San Juan River, New Mexico and Utah. Environmental Biology of Fishes, 1997,49 (4) : 417-434.

[18] Pingram MA, Collier KJ, Hamilton DP et al. Spatial and temporal patterns of carbon flow in a temperate, large river food web. Hydrobiologia, 2014,729(1): 107-131.

[19] 张 亮. 长江三峡江段鱼类碳、氮稳定性同位素研究 [学位论文]. 武汉: 中国科学院水生生物研究所, 2007.

[20] Rasmussen JB, Trudeau V. How well are velocity effects on $\delta^{13} \mathrm{C}$ signatures transmitted up the food web from algae to fish? Freshwater Biology, 2010,55(6) : 1303-1314.

[21] Thorp JH, Delong MD, Greenwood KS et al. Isotopic analysis of three food web theories in constricted and floodplain regions of a large river. Oecologia, $1998,117(6)$ : 551-563.

[22] Leigh C, Burford MA, Sheldon F et al. Dynamic stability in dry season food webs within tropical floodplain rivers. Marine and Freshwater Research, 2010,61(3): 357-368.

[23] Peterson BJ. Stable isotopes as tracers of organic matter input and transfer in benthic food webs: A review. Acta OecologiaInternational Journal of Ecology, $1999, \mathbf{2 0}$ (4) : 479-487.

[24] Lake JL, McKinney RA, Osterman FA et al. Stable nitrogen isotopes as indicators of anthropogenic activities in small freshwater systems. Candian Journal of Fisheries and Aquatic Sciences, 58( 5 ) : 870-878.

[25] Xu J, Xie P, Zang M et al. Variation in stable isotope signatures of seston and a zooplanktivorous fish in a eutrophic Chinese lake. Hydrobiologia, 2005,541 : 215-220.

[26] 王玉玉, 于秀波, 张 亮等. 应用碳、氮稳定同位素研究鄱阳湖枯水末期水生食物网结构. 生态学报, 2009,29 (3) : 1181-1188.

[27] 胡绵好, 袁菊红, 卢福财等. 鄱阳湖典型区段水体氮磷等污染发生频率与成因特征研究. 水资源与水工程学报, $2012,23(1): 14-17$.

[28] Tripe JA, Guy CS. Spatial and temporal variation in habitat and fish community characteristics in a Kansas Flint Hills stream. Ecology of Freshwater Fish, 1999,8(4) : 216-226.

[29] Roach KA, Thorp JH, Delong MD. Influence of lateral gradients of hydrologic connectivity on trophic positions of fishes in the Upper Mississippi River. Freshwater Biology, 2009,54(3) : 607-620.

[30] Allan JD. Landscapes and riverscapes: the influence of land use on stream ecosystems. Annual Review of Ecology and Systematics, $2004, \mathbf{3 5}:$ 257-284.

[31] England LE, Rosemond AD. Small reductions in forest cover weaken terrestrial-aquatic linkages in headwater streams. Freshwater Biology, 2004,49(6) : 721-734.

[32] Calizza E, Costantini ML, Rossi D. Effects of disturbance on an urban river food web. Freshwater Biology, 2012,57 (12) : 2613-2628. 